\title{
DETERMINAÇÃO DAS MELHORES CONDIÇÕES OPERACIONAIS DO PROCESSO DE PRODUÇÃO DA RICOTA*
}

\author{
LIA DE MENDONÇA PORTO** \\ RINALDO CARDOSO DOS SANTOS*** \\ TÂNIA LÚCIA SANTOS MIRANDA****
}

\begin{abstract}
Neste trabalho foram analisadas as melhores condições operacionais de produção de ricota, visando avaliar a agregação de valor desse processo ao soro do queijo e diminuição de seu potencial poluente. Desenvolveu-se planejamento fatorial $2^{3}$, considerando as seguintes variáveis: tempo de precipitação, temperatura e $\mathrm{pH}$ nos quais seria possível a obtenção das ricotas produzidas com soro puro e com adição de leite e leite em pó desnatado ao soro. Os resultados foram analisados em relação à recuperação de proteína existente na mistura inicial (soro+leite), aos teores de lactose e gordura nos soros e a demanda química de oxigênio (DQO) do soro antes e depois da produção para analisar seu efeito poluidor. Obteve-se melhor condição de produção em pH 5,0 e temperatura de $92^{\circ} \mathrm{C}$. O tempo de precipitação não apresentou grande influência no processo e a DQO mostrou-se dependente do teor de lactose do soro. Efetuou-se avaliação da viabilidade econômica do processo com e sem a adição de leite, bem como avaliação sensorial das ricotas economicamente viáveis. Não houve diferença na aceitação entre as ricotas. O leite deve ser adicionado em pequenas quantidades, ainda que com elevação de custo para melhorar as condições de coleta da massa da ricota no processo.
\end{abstract}

PALAVRAS-CHAVE: SORO; QUEIJO; RICOTA.

* Parte da dissertação de mestrado da primeira autora.

** Mestre em Engenharia Química, Universidade Federal de Minas Gerais (UFMG), Belo Horizonte, Doutoranda em Engenharia Química, Departamento de Processos Biotecnológicos, Universidade Estadual de Campinas (UNICAMP), Campinas, SP (e-mail: liaporto@hotmail.com).

*** Professor Adjunto IV, Doutor em Bioquímica, Departamento de Alimentos, Escola de Nutrição, Universidade Federal de Ouro Preto.

**** Professor Adjunto IV, Doutor em Bioquímica e Imunologia, Departamento de Engenharia Química, Escola de Engenharia, UFMG. 


\section{INTRODUÇÃO}

O soro constitui subproduto do processamento de queijo, da caseína e de outros laticínios acidificados. Contém a metade do extrato seco do leite, que é composto por lactose, proteínas e sais. Do volume de leite destinado à fabricação de queijos, entre 75 e $85 \%$ resulta em soro (ZADOW, 1997). Cinqüenta por cento da produção mundial de soro é tratada e transformada em produtos alimentares diversos, sendo quase a metade desse total usada diretamente na forma líquida $(S I S O, 1996)$.

Tem sido verificado grande potencial de crescimento para os produtos do soro no Brasil. A expressiva produção brasileira de queijo gera grande quantidade dessa matéria-prima, ainda sub-aproveitada. Pequena parte do soro é empregada na fabricação de ricota e na produção de bebidas lácteas (ALMEIDA, BOSSANI e ROIG, 2001), sendo mais comum a utilização do soro na alimentação de suínos ou seu lançamento em rios (PONSANO, PINTO e CASTRO-GOMES, 1992).

O soro lácteo (em si) não é poluente, mas quando lançado em cursos d'água provoca enorme efeito poluidor pelo consumo de oxigênio que reduz a vida aquática. $O$ soro do queijo apresenta potencial poluidor, aproximadamente, 100 vezes maior que o do esgoto doméstico. Quando descartado no solo compromete sua estrutura fisico-química e diminui o rendimento da colheita (CONDACK, 1993; PONSANO, PINTO e CASTROGOMES,1992).

Industrialmente, o soro pode ser processado mediante diversas técnicas, tais como filtração, centrifugação, evaporação, secagem, ultrafiltração, osmose reversa, tratamento térmico, fermentação, adição de ingredientes, desmineralização e cristalização, entre outras. As técnicas convencionalmente utilizadas para concentração do soro, em geral, necessitam de alta quantidade de energia, devido aos grandes volumes a serem trabalhados, e/ou apresentam problemas de escalonamento (VICENTE, CENZANO e VICENTE, 1996).

Pela acidificação do soro, sob aquecimento, pode-se obter a precipitação de grande parte de suas proteínas e produzir a ricota. Tal técnica constitui alternativa para o aproveitamento do soro (ZADOW,1997).

A utilização do soro como matéria-prima é importante, tanto sob o ponto de vista econômico como nutricional, devido seu alto valor biológico e alta digestibilidade. Além disso, apresenta equilibrado perfil de 
aminoáciodos essenciais, ausência de substâncias tóxicas, funcionalidade superior em alimentos lácteos acidificados, sabor e aroma suaves (PROTEÍNAS, 2000).

Propõe-se, neste trabalho, o estudo de algumas variáveis que influenciam o processo de precipitação das proteínas do soro na produção da ricota, visando analisar o processo sob o ponto de vista econômico (agregação de valor) e a diminuição de seu efeito poluidor.

\section{MATERIAL E METODOS}

A metodologia empregada envolveu a elaboração de queijo Minas frescal e, em seguida, a produção da ricota a partir do soro gerado. O trabalho foi desenvolvido primeiro em escala de laboratório, utilizando-se $1 \mathrm{~L}$ de leite na produção de queijo e $150 \mathrm{~mL}$ de mistura inicial (soro ou soro+queijo) visando determinar a influência de cada variável estudada sobre o processo de produção da ricota. A segunda etapa do trabalho ocorreu em escala piloto, sendo usadas bateladas de $43 \mathrm{~L}$ de leite para obtenção de quantidade suficiente de soro que permitisse a produção de ricota (em quantidade adequada) para a realização da avaliação sensorial. Os procedimentos e resultados só foram apresentados separadamente quando houve diferença significativa entre as duas etapas.

As produções em laboratório iniciaram-se com testes de avaliação do tempo de precipitação das proteínas para que fosse efetuada a retirada da massa. O intervalo utilizado foi de instantâneo a 30 minutos, com intervalos de 5 minutos, sendo mantidas fixas as variáveis $\mathrm{pH}$ em 4,8 e temperatura de $88^{\circ} \mathrm{C}$. Em seguida foram efetuados testes para avaliação da temperatura de operação no intervalo de 60 a $92^{\circ} \mathrm{C}$, mantendo-se fixas as variáveis $\mathrm{pH}$ em 4,8 e tempo de precipitação de 10 minutos. No estudo sobre o efeito do $\mathrm{pH}$ na precipitação das proteínas no soro foram usados valores entre 6,23 (pH do soro após a produção de queijo) e 3,00, sendo as variáveis temperatura e tempo de precipitação fixadas em $88^{\circ} \mathrm{C}$ e 10 minutos, respectivamente. Desta forma, foram avaliadas as condições operacionais nas quais era possível a obtenção das ricotas (precipitação e recuperação das proteínas). Com os resultados obtidos nessa etapa foi possível definir dois níveis de trabalho para cada uma das variáveis estudadas, auxiliando na elaboração do planejamento fatorial dos experimentos.

Os experimentos relativos ao planejamento fatorial foram efetuados para 
produção da ricota com soro puro e com adição de leites pasteurizado e em pó desnatado. A adição de leite ocorreu nas proporções de 10, 20 e $30 \%$ em relação ao volume de soro. Na adição de leite em pó desnatado considerou-se o teor de $10 \%$ de sólidos totais no leite, sendo os cálculos efetuados para adição correspondente a 10, 20 e 30\% de leite.

Durante todo o trabalho utilizou-se o termo mistura inicial para o soro puro ou adicionado de leite pasteurizado ou de leite em pó desnatado, isto é, volume inicial de todos os componentes da mistura processada. Efetuou-se o aquecimento da mistura inicial até a temperatura de operação, adicionando solução de ácido acético glacial (4:1) até a obtenção do pH de operação. Realizou-se suave agitação para homogeneização, sendo a mistura mantida em repouso durante o tempo de precipitação até a coleta da massa. Transferiu-se a massa para recipiente de tela, visando dessoramento, que ocorreu sob refrigeração.

Para o estudo preliminar da viabilidade econômica foram usados dados cedidos pela Cooperativa Regional de Produtores Rurais de Sete Lagoas (MG), referentes ao mês de maio de 2001 (Tabela 1). Os cálculos foram realizados sem considerar a implantação de novos equipamentos na empresa, tendo em vista que pode ser utilizado o mesmo equipamento da produção de queijo. Desta forma, a implantação do processo na indústria foi avaliada quanto ao custo de matéria-prima, embalagem, energia, limpeza e mão-de-obra. Não se agregou valor ao soro, levando em conta que o mesmo seria descartado pela indústria.

\section{TABELA 1 - PREÇOS DAS MATÉRIAS-PRIMAS, DO CUSTO DE PROCESSO E DO VALOR AGREGADO À RICOTA, CEDIDOS PELA COOPERATIVA REGIONAL DE PRODUTORES RURAIS DE SETE LAGOAS (MG) - MAIO DE 2001}

\begin{tabular}{ll}
\hline PRODUTO & PRECO \\
\hline Leite pasteurizado & $\mathrm{R} \$ 0,37 / \mathrm{L}$ de leite \\
Leite em pó desnatado & $\mathrm{R} \$ 7,00 / \mathrm{kg}$ de leite em pó \\
Ricota & $\mathrm{R} \$ 3,40 / \mathrm{kg}$ de ricota \\
Custo de processo & $\mathrm{R} \$ 1,25 / \mathrm{kg}$ de ricota \\
\hline
\end{tabular}

A avaliação sensorial das ricotas produzidas com soro puro e com adição de 5 e $10 \%$ de leite ao soro foi realizada por 23 julgadores, alunos do curso de Nutrição da Universidade Federal de Ouro Preto. Foram avaliados os atributos aparência, textura e sabor, mediante escala hedônica de 
cinco pontos (FARIA, MORI e YOTSUYANAGI, 2000).

Nas produções em escala piloto, a temperatura de operação foi de $88^{\circ} \mathrm{C}$ e o ácido acético glacial adicionado na proporção de 0,03\% com relação à mistura inicial. As ricotas foram produzidas com soro puro e com a adição de $5 \%$ e $10 \%$ de leite pasteurizado, totalizando $25 \mathrm{~L}$ de matériaprima em batelada.

Nos soros provenientes do queijo e da ricota foram analisados os teores de lactose, lipídios, proteínas e a acidez (INSTITUTO ADOLFO LUTZ, 1985). Efetuou-se a análise microbiológica de coliformes conforme a APHA (1992) e a de demanda química de oxigênio (DQO) de acordo com GOBBI e BATTISTELLA (1999).

\section{RESULTADOS E DISCUSSÃO}

O estudo do efeito da temperatura na precipitação de proteínas do soro com pH de operação de 4,8 e tempo de 30 minutos possibilitou a escolha de dois níveis para o planejamento fatorial, sendo $82^{\circ} \mathrm{C}$ o nível baixo e $92^{\circ}$ C o nível alto da temperatura.

A avaliação da influência do pH no processo de produção da ricota, com temperatura de operação fixada em $88^{\circ} \mathrm{C}$ e o tempo de precipitação de 30 minutos, permitiu definir os níveis (baixo 4 e alto 5) de operação desta variável para o planejamento fatorial. Os valores obtidos coincidiram com o ponto isoelétrico da albumina $(4,65)$ citado na literatura (SPREER, 1973).

Pelo estudo do tempo de precipitação definiu-se o nível alto como sendo 30 minutos e o baixo de 3 minutos, considerando o tempo necessário para homogeneização da mistura inicial.

A produção da ricota com soro lácteo puro ou com adição de leites pasteurizado e em pó desnatado apresentou condição de operação ótima com temperatura do processo de $92^{\circ} \mathrm{C}$ e pH 5,00 (Tabela 2). Os resultados de retenção de lactose no soro e DQO encontram-se também na Tabela 2.

A adição de leite ao soro melhorou o rendimento do processo devido à associação das soroproteínas com as micelas de caseína (OLDFIELD et al., 2000). A percentagem de proteína precipitada (Tabela 2) aumentou 
com a adição de leites pasteurizado e em pó desnatado, assim como o rendimento do processo. O teor de lactose permaneceu praticamente inalterado no soro da ricota com a adição de leite pasteurizado. No entanto, ocorreu aumento considerável com a adição do leite em pó desnatado. Tratando-se de açúcar fermentescível, a lactose poderia ser removida por bioprocessamento como ocorre com efluentes de outras indústrias alimentícias (BEUX et al. 2003).

\section{TABELA 2 - TEMPO DE PRECIPITAÇÃO, RECUPERAÇÃO DE PROTEÍNA, RETENÇÃO DE LACTOSE NO SORO DAS DIVERSAS MISTURAS E DQO, A 92으 E pH 5,0}

\begin{tabular}{lllll}
\hline Mistura inicial & $\%$ & $\%$ & $\%$ & DQ0* \\
(tempo de precipitação - min) & de proténa & precipitada & de lactose & (ppm) \\
\hline Soro puro (30) & 0,79 & 33,47 & 4,93 & 35,761 \\
+10\% de leite (3) & 0,69 & 40,96 & 4,95 & 35,744 \\
+20\% de leite (3) & 0,69 & 40,30 & 4,97 & 37,336 \\
+30\% de leite (3) & 0,69 & 58,82 & 5,06 & 38,334 \\
+10\% de leite em pó (3) & 0,89 & 37,96 & 5,23 & 50,834 \\
+20\% de leite em pó desnatado (3) & 0,91 & 48,56 & 6,20 & 62,861 \\
+30\% de leite em pó desnatado (3) & 0,92 & 65,31 & 7,93 & 65,742 \\
\hline
\end{tabular}

(*) Demanda Química de Oxigênio.

O teor de lipídios nos soros após a produção das ricotas apresentaram valores inferiores a $0,1 \%$, indicando que praticamente toda a gordura da mistura inicial foi carreada juntamente com as proteínas. Desta forma, quanto mais lipídios houver na mistura inicial, maior será o percentual de gordura na ricota produzida.

A adição de leite ao soro na produção da ricota provocou diminuição na receita da empresa, devido aos gastos com matéria-prima (Tabela 3). A adição de leite pasteurizado ao soro para a produção da ricota só foi viável economicamente até o volume de $10 \%$, quando os processos apresentam lucro (quanto mais leite é utilizado, menor o lucro obtido pela empresa). Grande parte das indústrias utiliza adição de leite no processo apesar da diminuição na receita, provavelmente para facilitar o 
manuseio na coleta da massa e melhorar as características de textura da ricota.

O leite em pó (por ser mais caro) eleva o custo da matéria-prima, porém a adição de sólidos no volume total melhora o rendimento. $O$ aumento no rendimento não é suficiente para tornar o processo lucrativo, conforme os dados cedidos pela Cooperativa Regional de Produtores de Sete Lagoas (maio de 2001).

TABELA 3 - QUANTIDADE DE MATÉRIA-PRIMA UTILIZADA, CUSTO E RECEITA LÍQUIDA OBTIDA NO PROCESSO DE PRODUÇÃO DA RICOTA PARA 100 LITROS DE VOLUME TOTAL PROCESSADO (MAIO/2001)

\begin{tabular}{l|l|l|l|l}
\hline Soro (L) & Leite (L) & $\begin{array}{l}\text { Leite em pó } \\
\text { desnatado }(\mathrm{Kg})\end{array}$ & Custo Total (R\$) & Receita Liquida (R\$) \\
\hline 100 & 0 & 0 & 1,800 & 1,600 \\
95 & 5 & 0 & 2,535 & 0,865 \\
90 & 10 & 0 & 2,896 & 0,504 \\
90 & 20 & 0 & 3,795 & $-0,395$ \\
70 & 30 & 0 & 4,250 & $-0,850$ \\
100 & 0 & 1,1 & 4,358 & $-0,958$ \\
100 & 0 & 2,5 & 5,465 & $-2,065$ \\
100 & 0 & 4,3 & 4,902 & $-1,503$ \\
\hline
\end{tabular}

Como o estudo da viabilidade econômica do processo de produção da ricota indicou lucro com a adição de leite até $10 \%$ da mistura inicial, as avaliações sensoriais foram feitas somente para as ricotas produzidas com soro puro ou com adição de $5 \%$ e $10 \%$ de leite.

De acordo com a avaliação sensorial, apresentada na Tabela 4, a aceitação das ricotas produzidas com e sem a adição de leite mostrou-se, praticamente, a mesma. Era de se esperar que toda a produção de ricota das empresas de laticínios ocorresse sem nenhuma adição de leite. Entretanto, esse fato não é constatado devido à sensível melhoria que a adição de leite proporciona nas condições operacionais do processo. Deve-se salientar que a melhoria das condições operacionais não implica 


\title{
TABELA 4 - MÉDIA DOS VALORES ATRIBUÍDOS AOS ITENS DA AVALIAÇÃO SENSORIAL NOVE DIAS APÓS A PRODUÇÃO DA RICOTA, UTILIZANDO ESCALA HEDÔNICA DE CINCO PONTOS
}

\begin{tabular}{llll}
\hline Ricota & Aparência & Textura & Sabor \\
\hline Sem leite & $3,56 \pm 0,90$ & $3,94 \pm 0,95$ & $3,50 \pm 1,02$ \\
Com 5\% de leite & $3,63 \pm 0,95$ & $3,44 \pm 1,02$ & $3,50 \pm 1,11$ \\
Com 10\% de leite & $3,88 \pm 1,05$ & $3,94 \pm 0,80$ & $3,94 \pm 1,18$ \\
\hline
\end{tabular}

\section{CONCLUSÃO}

A recuperação de grande parte das proteínas do soro, visando seu aproveitamento na produção da ricota diminui o desperdício dessa matériaprima e agrega valor ao soro. A adição de leite ao soro melhora o rendimento do processo, porém a retirada das proteínas não exerce grande influência na redução do seu efeito poluidor. Esse constituinte permanece inalterado com a precipitação das proteínas, devido ao alto teor de lactose, tornando necessária a utilização de método adicional para sua retirada.

\begin{abstract}
DETERMINATION OF THE BEST OPERATIONAL CONDITIONS FOR THE RICOTTA PRODUCING PROCESS

The best of operational conditions for the ricotta producing process were analyzed in this work, aiming to evaluate the value addition of this process to cheese whey and reducing its pollutant potential. A factorial $2^{3}$ scheme was developed considering the following variables: time of precipitation, temperature and $\mathrm{pH}$ in which ricotta obtention was possible when prepared from pure whey and with the addition of milk or powdered skim-milk. Results were analysed in relation to the recovery of protein existing in the initial blend (whey+milk), to lactose and fat content of the wheys and to the chemical oxygen demand (COD) of the wheys before and after the production in order to analyze the pollutant effect. The best operational conditions were obtained at $\mathrm{pH} 5.0$ and $92^{\circ} \mathrm{C}$. Time of precipitation did not show great influence in the process and COD was shown as being dependent on the lactose content of the whey. Evaluation of the economical viability of the process was also performed with and without milk addition, as well as a sensory evaluation of the economically viable ricottas. There was no difference in acceptation among the ricottas. Although milk must be added to whey in
\end{abstract}


small amounts, even with cost increase, in order to improve the ricotta mass recovery conditions in the process.

KEY-WORDS: WHEY; CHEESE; RICOTTA.

\section{REFERÊNCIAS}

1 APHA. American Public Health Association. Standard Methods For the Examination of Water and Wastewater. $18^{\text {th }}$ ed. Washington, 1992.

2 ALMEIDA, K.; BONASSI, I.; ROÇA, R. O. Características físicas e químicas de bebidas lácteas fermentadas e preparadas com soro de queijo minas frescal. Ciência e Tecnologia de Alimentos, Campinas, v.21, n.2, p.187-192, 2001.

3 BEUX, M. R.; YAMAMOTO, C. I.; WINTER, C. M. G et al. Bioprocess applied to the treatment of residual waters of coffee wet processing for the incorporation of selected yeast strains. Boletim do CEPPA, Curitiba, v. 21, n. 2, p. 379-392, 2003.

CONDACK, J. Ultrafiltração do soro de queijo: parâmetros operacionais e utilização do concentrado protéico na fabricação de requeijão cremoso. 1993. p.120. Dissertação (Mestrado), Universidade Federal de Viçosa (UFV), Viçosa.

FARIA, E. V.; MORI, E. E. M.; YOTSUYANAGI, K. Técnicas de análise sensorial. Campinas: Instituto de Tecnologia de Alimentos, 2000. $116 \mathrm{p}$.

GOBBI, D.L.; BATTISTELLA, E.C. Determinação semimicro da demanda química de oxigênio aplicado na análise de efluentes e em águas superficiais. In: ENCONTRO NACIONAL DE QUÍMICA ANALÍTICA, 10., Santa Maria, RS , 1999. Livro de Resumos... Imprensa Universitária UFSM, 1999. p. QA-37

$7 \quad$ IAL. Normas analíticas do Instituto Adolfo Lutz: métodos químicos e físicos para análise de alimentos. 3. ed. São Paulo, 1985. v.1.

OLDFIELD, D.J.; SINGH H.; TAYLOR M.W.; PEACE, K.N. Heat-induced interaction of beta-lactoglobulin and alfa-lactoalbumin with the casein micelle in $\mathrm{pH}$ adjusted skim milk. International Dairy Journal, Alberta, v.10, n.8, p. 509-518, 2000.

PONSANO, E.H.G.; PINTO, M.F.; CASTRO-GOMES, R.J. Soro de leite: obtenção, características e aproveitamento: revisão. Semina Ciência Agrícola , Londrina, v.13, n. 1, p. 92-96, 1992. 
10 SISO, M. I. G. The biological utilization of cheese whey: a review. Bioresource Technology, Essex, v.57, n.1, p.1-11, 1996.

11 SPREER, E. Lactologia Industrial. Acriba, Espanha: Ed.Zaragoza, 1973.

12 PROTEÍNAS do soro em produtos nutricionais. USDEC News, São Paulo, v.3, n.1, p.1-8, jul.2000.

13 VICENTE, AM; CENZANO, I.; VICENTE, JM. Manual de indústrias de alimentos. São Paulo: Varela, 1996.

14 ZADOW, J.G., Modern dairy technology: advances in milk processing. London: Elsevier,1997. v. 2. 